\title{
DE LA CUANTIFICACIÓN AL ESTADO MENTAL: UN ESTUDIO DEL VERBO VALER
}


En algunas variedades del español, el verbo valer, acompañado de un dativo (valerle), significa 'no importarle a alguien una cosa o persona'. El objetivo del presente estudio es trazar el camino evolutivo que llevó a este uso peculiar, en el que un enunciado afirmativo en su forma dispara una lectura de sentido negativo. Proponemos que el camino pasa por un fenómeno de "colocación", cuyo papel resulta ser fundamental. Las colocaciones están formadas con sustantivos gramaticalizados que aportan una noción cuantificativa de escaso valor (valer un comino = valer muy poco), y establecen el escenario dentro del cual valer se desliza hacia el campo mental en presencia de un experimentante dativo ( $m e$ vale un comino = me importa muy poco), adoptado, según nuestra hipótesis, por imitación del verbo importar que co-ocurre con los mismos sustantivos. El camino desemboca en el uso antes referido mediante la supresión del elemento cuantificativo de las colocaciones.

Palabras Clave: colocación, cuantificación, dativo, gramaticalización, verbos mentales

In some varieties of Spanish, the verb valer 'to be worth' accompanied by a dative (valerle) means 'to be of no importance to someone. The objective of the present study is to trace the evolutionary path that led to this peculiar use, in which a formally affirmative expression implies a negation. We propose that the evolution encompasses a phenomenon of "collocation", whose role turns out to be crucial. The collocations are formed with grammaticalized nouns that contribute a quantifying notion of low value (valer un comino 'to be worth a cumin' = 'to be worth very little'), and set the stage for the emergence of the mental interpretation in the presence of a dative experiencer (me vale un comino = 'it matters very little to me', 'I couldn't care less'), adopted, according to our hypothesis, on the model of the verb importar 'to matter', which co-occurs with the same nouns. The evolutionary path culminates in the above-mentioned use through the elimination of the quantifying element of the collocations.

KeYS wORDS: collocation, dative, grammaticalization, mental verbs, quantification

RECEPCIÓN: 5/04/2015

ACEPTACión: 18/05/2015 


\title{
DE LA CUANTIFICACIÓN AL ESTADO MENTAL: UN ESTUDIO DEL VERBO VALER
}

\author{
Elenor Arrington Báez \\ Instituto Francisco Xavier Alegre \\ Chantal Melis \\ Universidad Nacional Autónoma de México
}

\section{Introducción}

El presente trabajo tiene por objetivo esbozar el camino histórico que lleva a un empleo peculiar del verbo valer, propio de algunas regiones hispanohablantes, en el que el verbo unido a un objeto indirecto significa 'no importarle a alguien una cosa o persona':

(1) a. ¡Me vale! Para mí lo nuestro terminó para siempre (Felipe Victoria Zepeda, La casta divina. Historia de una narcodedocracia, Novela sobre la impunidad presidencial, 1995, CREA)

b. Se encogió de hombros, "me vale", trató de convencerse (Jenny E. Hayen, Por la calle de los anhelos, 1993, CREA) 
La peculiaridad de este empleo radica en que una estructura afirmativa en la superficie dispare una lectura de sentido negativo ( $m e$ vale $=$ no me importa), con un verbo que, además, remite a una noción orientada positivamente, según manifiestan las siguientes definiciones de valor: "cualidad de las cosas que valen, o sea, que tienen cierto mérito, utilidad o precio" (DUE, 2000, s.v. valor); "grado de utilidad o aptitud de las cosas, para satisfacer las necesidades o proporcionar bienestar o deleite" (DRAE, 2001, s.v. valor). ${ }^{1}$

Para cumplir con nuestro objetivo, seguiremos el desarrollo de valer a través del tiempo, poniendo especial atención en algunas construcciones que facilitaron el movimiento gradual de valer hacia el uso ilustrado en (1). El estudio diacrónico que aquí ofrecemos parte del trabajo de Arrington Báez (2014), en el que se encuentra resumida la historia completa de este verbo polisémico, y tiene como base el mismo conjunto de datos extraídos del Corpus Diacrónico del Español (CORDE) y del Corpus de Referencia del Español Actual (CREA), ambos de la Real Academia Española. Los datos suman 1,300 ocurrencias de valer, distribuidas de manera más o menos equitativa entre los siglos XIII (inicios documentables de la lengua), xviI (periodo clásico) y $\mathrm{xx}$ (español moderno). ${ }^{2}$

\footnotetext{
${ }^{1}$ Las siglas DuE se refieren al Diccionario de uso del español de María Moliner (2000) y las siglas DRAE, al Diccionario de la lengua española de la Real Academia Española.

${ }^{2}$ Con el fin de asegurar cierto grado de homogeneidad en cuanto a la naturaleza de las documentaciones, la recolección de datos se hizo en torno a determinadas 'temáticas' ya establecidas en los corpus consultados. Así, para los datos del corDE se utilizaron las categorías de 'narrativa', 'didáctica' e 'historia y documentos'. Por lo que al siglo XIII se refiere, dada la escasez de la documentación, también
} 
La evolución semántica de valer que pretendemos describir estará centrada en los usos cuantificados del verbo. Veremos que valer admite con facilidad complementos de cantidad porque denota la propiedad de 'tener valor' que se puede graduar (valer mucho, valer poco). Esta característica dará paso a un fenómeno de "colocación", de acuerdo con el cual valer empezará a combinarse de manera recurrente con determinados sustantivos (tales como pepino, comino y ble$d o$ ), que en el seno de estas colocaciones asumen una función cuantificativa orientada hacia el polo negativo de una escala de evaluación (valer muy poco). Argumentaremos que dicho patrón combinatorio se gestó sobre el modelo del verbo importar, el cual afianzó aquellas colocaciones antes que valer y en la actualidad las exhibe con índices de frecuencia mucho más altos que valer en todas las variedades del español. También mostraremos que a partir de ahí la evolución subsecuente de valer, en algunos países como México, se puede explicar. Será dentro del ámbito de aquellas colocaciones que valer adquirirá el significado mental de 'importar', mediante la introducción de una entidad codificada como objeto indirecto con papel de "experimentante", para moverse luego en dirección a la estructura afirmativa con sentido negativo que ejemplificamos arriba (me vale $=$ no me importa).

El trabajo está organizado de la siguiente manera: en el apartado 2 discutimos brevemente el comportamiento de

se incluyeron textos recopilados bajo el tema de 'derecho'. Por otra parte, en relación con el CREA, se utilizaron las categorías de 'novela y relatos', 'ética', 'filosofía' e 'historia'. Para obtener una muestra representativa del comportamiento de valer, se recogieron ejemplos y usos en distintos tiempos, modos y personas gramaticales (véase Arrington Báez, 2014). 
VALĒRE en latín con el fin de precisar la herencia semántica de valer. El apartado 3 resume el panorama diacrónico de las construcciones de valer con complementos de cantidad. En el apartado 4 abordamos las colocaciones, de formación tardía, en las que valer se une a sustantivos que evocan cosas de poco valor, examinamos el proceso de gramaticalización que subyace a estas estructuras cuantificadas, y ponemos en evidencia la influencia que el verbo importar ejerció sobre valer en el ámbito específico de las mencionadas colocaciones. En el apartado 5 seguimos ocupándonos de éstas para mostrar cómo en algunas variedades del español, y de manera sobresaliente en México, valer extiende su significado al dominio mental ('importar') en presencia de un experimentante dativo, adoptado por imitación del verbo importar. El apartado 6 se encarga de la génesis de la frase me (te, le) vale, ilustrada en (1), cuyo significado se relaciona con las colocaciones anteriores, pese a la supresión del sustantivo cuantificador que aporta la noción negativa. Finalmente, en la sección de conclusiones, evaluamos la historia de valer desde la perspectiva universal de los estudios dedicados al cambio semántico.

\section{El origen de valer}

El verbo valer proviene del latín VALĒRE, cuyo significado original remitía a la noción física de 'ser fuerte, robusto, vigoroso’ y se extendía, por procesos metafóricos, a la caracterización del que 'tiene poder' en el ámbito militar, político o social (Pimentel Álvarez, 1996, s.v. valeo). Además, ya 
en latín, VALĒRE podía combinarse con sujetos inanimados a los que se les atribuía la propiedad de 'tener valor' — una propiedad poco específica, que tomaba distintos matices, tales como 'tener mérito, 'servir', 'tener vigencia' o 'ser eficaz', según el contexto en que se emitía la valoración:

(2) a. mos maiorum, ut lex, valebat 'la costumbre de los maiores valía comoley' (Cic. Leg.2,23)

b. nescis quo valeat nummus 'no sabes para qué sirve el dinero' (Hor. S. 1, 1,73)

c. ratus repentinum valiturum terrorem 'pensando que un terror repentino sería eficaz' (Liv. 44, $31,6)$

d. praemia apud me minimum valent 'los premios no tienen el menor valor ante mí' (Cic. Fam. $1,9,11)$

La evolución semántica de VALĒRE pone de relieve, nuevamente, la tendencia de las palabras a generar acepciones más abstractas a partir de sentidos más concretos (Heine, Claudi y Hünnemeyer, 1991; Sweetser, 1990). En este caso, el deslizamiento desde la fuerza física hacia el valor pudo darse con naturalidad a través del paso por la idea de algo 'bueno', pues tal como se admira a las personas fuertes, así reconocerle a una cosa cierto valor es ver en ésta un aspecto deseable, bueno, positivo.

El punto de mayor interés para nuestros objetivos es que, tanto en su acepción 'ser fuerte' cuanto en 'tener valor', VALĒRE expresa una propiedad, como suelen hacerlo los adjetivos. De manera más específica, VALĒRE evoca el tipo de 
propiedad que se asocia con los llamados adjetivos "calificativos", los cuales se distinguen por poseer, en su mayoría, un significado de grado (Demonte, 1999: 173). Es decir, al igual que estos adjetivos, VALĒRE remite a cualidades que pueden proyectarse sobre una escala y concebirse en términos de 'más o menos': ser muy fuerte o no demasiado fuerte; tener mucho o poco valor. La posesión de este rasgo implica que VALĒRE no encuentra obstáculo alguno para combinarse con un cuantificador de grado, como de hecho ocurre en (2d) citado arriba (cf. minimum), entendiéndose por cuantificador de grado "cualquier medio gramatical que exprese cantidad, número o intensidad de una determinada realidad o cualidad de manera relativa respecto de una escala" (Sánchez López, 1999: 1090). Como se verá, los cuantificadores de grado van a jugar un papel importante en la historia de valer.

\section{Valer y la cuantificación}

El estudio diacrónico de valer arroja un panorama muy complejo de usos y sentidos vinculados a determinadas estructuras. En el mencionado trabajo de Arrington Báez (2014) se muestra que el comportamiento polisémico de $v a$ ler gira en torno a dos grandes ámbitos de significación. El primero abarca distintas construcciones en las que valer se limita a atribuir a una persona o cosa la propiedad de 'tener valor' (con sus variables matices); el segundo reúne todos los empleos del verbo en los que el valor asignado al sujeto de la predicación se cuantifica en presencia de un elemento 
adicional que hace referencia a la magnitud del valor. ${ }^{3} \mathrm{Am}$ bas vertientes semánticas están perfectamente establecidas desde los primeros testimonios del español, aunque en este trabajo discutiremos únicamente los empleos cuantificados de valer, debido a la naturaleza del tema que nos ocupa.

Con base en el estudio de Arrington Báez (2014), empezamos por ilustrar los contextos prototípicos en que valer se acopla a una noción cuantificativa. En el primer caso, si bien poco frecuente en el corpus recopilado, valer se combina con un cuantificador "numeral" de tipo "cardinal" (Sánchez López, 1999), cuya principal característica, como miembro de dicha subclase, es la de expresar una cantidad exacta:

(3) a. A omne de ssu criazon deue dar por el priujllegio o por la carta veynte marauedis ssi el heredamjento valiere de rrenta çiento marauedis (Anónimo, Espéculo de Alfonso X. BM10123, c. 1260, CORDE)

b. Una chanza a tiempo vale ocho escudos, si no se ha dicho, si es vieja, merece perdón de un disparate (Baptista Remiro de Navarra, Los peligros de Madrid, 1646, CoRDE)

c. El pasaporte vale cincuenta soles (José Eustasio Rivera, La vorágine, 1924, CORDE)

\footnotetext{
${ }^{3}$ El primer grupo de construcciones contiene ejemplos tales como El hombre con conversación vale, al callado nadie lo escucha (Dante Medina, Cosas de cualquier familia, 1990, CREA); para las construcciones del segundo tipo, véase abajo. Valer presenta, además, toda una serie de extensiones semántico-sintácticas, que no se tratarán en el presente trabajo.
} 
En estos ejemplos, valer sirve para indicar el 'precio' de una cosa y actualiza una de sus acepciones recogidas por los diccionarios. ${ }^{4}$ Como sucede con otros verbos (medir, pesar, durar, costar, etc.), el sintagma cuantificativo que acompaña a valer está colocado en la frontera entre el objeto directo y un complemento de aspecto adverbial (Alarcos Llorach, 1994: 282; Di Tullio, 2007: 124-25). Lo cierto es que en su acepción 'precio', valer requiere la presencia del adyacente nominal.

En las demás construcciones cuantificadas, valer aparece con uno de los cuantificadores "indefinidos", que se diferencian de los "numerales" en denotar una cantidad de modo aproximado o impreciso, sin especificar número, y que incluyen elementos de diversa naturaleza (Sánchez López, 1999). Los que encontramos modificando a valer pertenecen al grupo de los "gradativos" o "escalares". Éstos se caracterizan por expresar un grado de cantidad, número o intensidad con que se toma una determinada realidad, esto es, por expresar una cantidad relativa respecto de algún parámetro que funciona a modo de escala (Sánchez López, 1999).

Forman parte de este grupo de cuantificadores los elementos comparativos (más, menos, tanto), cuya propiedad definitoria es la de establecer una relación entre dos puntos dentro de una escala. En uno de ellos se sitúa el elemento cuantificado, mientras que en el otro se establece el término de comparación. Según la posición relativa de ambos ele-

\footnotetext{
${ }^{4}$ Por ejemplo: "Ser el precio de una cosa cierta cantidad de dinero. La finca vale ocho mil euros más que el año pasado" (DUE, 2000, s.v. valer).
} 
mentos dentro de la escala, la comparación será de "superioridad”, “igualdad” o “inferioridad” (Sánchez López, 1999). Considérense los siguientes ejemplos elaborados con valer:

(4) a. Poca cosa que faga omne con saber vale más que mucha con torpedat (Anónimo, Libro de los cien capítulos, c. 1285, CORDE)

b. [...] porque toda su hacienda no vale tanto como esta buena nueva que yo le llevo (Alonso Jerónimo de Salas Barbadillo, La sabia Flora Malsabidilla, 1621, CORDE)

c. El mobiliario vale menos que su acarreo (Mariano Azuela, La luciérnaga, 1932, CORDE)

Las comparaciones de "superioridad" e "inferioridad" crean un intervalo en la escala entre los dos puntos comparados. Dicho intervalo permite la formación de construcciones en las que más y menos pueden ir precedidos por un cuantificador de grado no comparativo, como mucho o poco:

(5) a. Muchas aplicaciones hay en el mundo muy desaprovechadas porque son a cosas tan superfluas que el hacerlas muy bien vale poco más que el no hacerlas (Juan de Zabaleta, Errores celebrados, 1653, CORDE)

b. Tu madre vale mucho más que todos vosotros, contando a tu padre - me decía una vez (Pío Baroja, Desde la última vuelta del camino. Memorias, 1944-1949, CORDE)

En un tercer tipo de construcciones, se registra la presencia de algo, nada, mucho, poco y demasiado, los cuales, al 
unirse con valer, siempre se comportan como los denominados gradativos "proporcionales” (Sánchez López, 1999). En su caso, la escala visualizada contiene una magnitud - cierto grado de 'valor' - que actúa como punto de referencia implícito y corresponde a lo que el hablante considera ser una manifestación "normal" de la propiedad de 'tener valor', es decir, una magnitud que está conforme con sus expectativas. Aquí reside el aspecto "subjetivo" de este tipo de evaluación, en el sentido de que el cuantificador proporcional remite implícitamente a las creencias del hablante o su actitud ante lo dicho (Traugott, 1989, 1995). A partir de este punto de vista subjetivo, el hablante relaciona la intensidad del valor que presenta la entidad evaluada con una región alta o baja dentro de la escala. En el caso de valer, las relaciones se establecen en torno a una propiedad que se caracteriza por su orientación inherentemente positiva - recuérdense las definiciones de valor arriba apuntadas- y los cuantificadores sirven para reforzar o, por el contrario, atenuar el grado en que se aplica la propiedad, ${ }^{5}$ como se aprecia en estos ejemplos del corpus:

(6) a. Quien non á seso non á aver, quien non á aver non vale nada su seso, nin su saber (Anónimo, Libro de los cien capítulos, c. 1285, CORDE)

\footnotetext{
${ }^{5}$ En su trabajo sobre algunos cuantificadores del inglés, Paradis (1997) los describe como elementos que "elevan" (boosters) o "disminuyen" (diminishers) el grado de fuerza de la cualidad expresada.
} 
b. Soy tan malo en eso de divino que no sé si vale algo un disparate que he hecho [...] (Agustín de Rojas Villadrando, El viaje entretenido, 1603, CORDE)

c. La una sin la otra valen poco, y juntas pueden mucho (Baltasar Gracián, El Discreto, 1646, CORDE)

d. Tú vales mucho ipero mucho! aunque no lo creas (Tomás Carrasquilla, La marquesa de Yolombó, 1928, CORDE)

e. Si nosotros no podemos arriesgarnos, porque valemos demasiado, que vaya mi padrastro, pues si muere, poco se perderá (Martín de Riquer, Los cantares de gesta franceses (Sus problemas, su relación con España), 1952, CORDE)

Los cuantificadores mucho y demasiado indican que el sujeto posee la cualidad de 'valor' en una proporción superior a la media esperada, mientras que algo, poco y nada cuantifican en el sentido opuesto, sugiriendo una magnitud inferior a la norma o expectativa del hablante. Nótese que la orientación hacia el polo negativo de la escala puede llegar a expresar la ausencia de la propiedad en el sujeto (nada).

Sólo nos queda por observar que de manera ocasional se introduce un participante dativo en las estructuras cuantificadas:

(7) Más te vale un buen amigo que en tu troja mucho trigo (Pastor Servando Obligado, Tradiciones argentinas, 1903, CORDE)

Como sucede a menudo en español, estamos ante la presencia de un dativo - no previsto en la valencia del verbo-, que designa a una persona concebida como "interesada" en la situación que se enuncia. Más adelante, en cambio, 
examinaremos la incorporación de un dativo exigido por el nuevo significado mental de valer.

\section{Las colocaciones de sentido negativo con sustantivos gramaticalizados}

\subsection{Las colocaciones con valer}

Teniendo los contextos prototípicos como telón de fondo, vamos a enfocarnos en un tipo especial de cuantificación que cobra visibilidad en nuestro corpus de datos correspondiente al siglo $\mathrm{xx}$ :

(8) a. Esa discusión no vale un comino (José Eustasio Rivera, La vorágine, 1924, CORDE)

b. Escribí este "Nuevo Misántropo" porque se me ocurrió. ¿Molestarme para que lo estrenen? ¡Vamos! Además, no vale un pepino (Max Aub, La calle de Valverde, 1961, CORDE)

c. [...] y hablo de la muerte verdadera, aunque quizás no siendo yo filósofa, ni teóloga, ni siquiera española, toda esta conversación no valga un rábano (Alicia Steimberg, Su espíritu inocente, 1981, CREA)

d. Sin ella hubieras valido un cacahuate (Gilberto Chávez Jr., El batallador, 1986, CREA)

En la superficie, la unión de valer con un sintagma nominal recuerda los casos donde el verbo se utiliza para indicar el 'precio' de una cosa, pero es obvio que aquí $v a-$ 
ler no lleva esa acepción. La lectura que se desprende de los ejemplos en (8) es una evaluación de carácter negativo: las entidades en juego se descalifican por ser personas o cosas de escaso 'valor'. En estas oraciones, en efecto, los sintagmas nominales aportan la idea del ínfimo grado en que se presenta la cualidad referida y se comportan en ese sentido como los cuantificadores gradativos proporcionales que examinamos arriba. Específicamente, expresiones tales como valer un pepino o valer un cacahuate significan algo cercano a valer muy poco, con la diferencia de que los sustantivos en cuestión realzan la dimensión negativa del juicio, al imprimirle al enunciado cierta fuerza expresiva que no posee el cuantificador (muy) poco. En el fondo, estamos ante un fenómeno que se da con cierta frecuencia en el ámbito de las valoraciones escalares, donde se ha visto que elementos léxicos de distinta naturaleza tienden a desarrollar funciones cuantificativas que se caracterizan por su mayor "expresividad" (Paradis, 2000), como manifiestan en español frases tales como ipura tonteria!, bien malo, un perfecto majadero o una noche terriblemente fría.

Volviendo a los ejemplos de (8), podemos apreciar que los sintagmas nominales que nos ocupan son más comunes en oraciones negativas $(8 \mathrm{a}, \mathrm{b}, \mathrm{c})$. En estos casos, el sentido de 'muy poco' al que contribuye el sintagma nominal interactúa con el operador no, de tal manera que la valoración que realiza el hablante en una oración como Esa discusión no vale un comino se aproxima al significado que tendría Esa discusión no vale nada.

El empleo de valer con este tipo de cuantificador apunta a un fenómeno de "colocación". En palabras de Írsula Peña 
(1992: 160), las colocaciones son "las combinaciones frecuentes y preferentes de dos o más palabras, que se unen en el seno de una frase para expresar determinados acontecimientos en situaciones comunicativas establecidas". Dichas combinaciones se distinguen de las llamadas "unidades fraseológicas" en la medida en que conservan cierta flexibilidad formal - sus componentes pueden variar $-{ }^{6}$ y no presentan un significado idiomático, ${ }^{7}$ pero se asemejan a ellas en su funcionamiento como elementos "prefabricados" del discurso, socializados, memorizados y repetidos (Wotjak, 1998).

El carácter omnipresente de estas preferencias combinatorias en el habla ha empezado a despertar mucho interés entre los lingüistas (véase, por ejemplo, Bybee y Hopper, 2001), y está orientando los estudios del cambio lingüístico por rumbos cada vez más enfocados en cadenas de palabras que se procesan como unidades (Sinclair, 1991) y sufren alteraciones en el significado o la función de los elementos que las componen (véase Krug, 2001, entre otros).

En el caso que nos concierne, observamos una "predisposición colocacional" (Wotjak, 1998) entre el verbo valer y un sustantivo que aporta una noción cuantificativa por medio de su referencia a un objeto de escaso valor. Entre los nombres que recogimos en el corpus figuran pepino, comino, rábano, bledo, pimiento, cacahuate, gorro, pito y carajo. Desde el punto de vista semántico, parece ser que la infe-

\footnotetext{
${ }^{6}$ Generalmente se requiere por lo menos de un elemento léxico especificado (Gries, 2008: 6).

${ }^{7}$ Aunque uno de sus componentes suele tener un sentido figurado o especializado (Granger y Paquot, 2008: 36).
} 
rencia pragmática (Traugott y König, 1991; Traugott, 2004) que facilitó su interpretación como cuantificador se activó a través de una asociación entre el objeto designado y alguna propiedad susceptible de evocar una noción de "insignificancia”, es decir, como producto de una metonimia.

Para dar sustento a esta hipótesis, conviene hacer notar, en primera instancia, que los sustantivos en cuestión se relacionan sobre todo con plantas o los frutos de éstas, salvo gorro, pito y carajo. Algunos denotan plantas rastreras como lo son el pepino, el cacahuate y el bledo, que se caracterizan por expandirse rápidamente y generar nuevas plantas a partir de nudos, lo cual provoca que la producción de sus frutos sea vasta y por ende muy común. Otros se refieren a plantas cuya parte comestible es de muy pequeño tamaño, como sucede con la semilla del comino, la raíz del rábano y el fruto del cacahuate. Además, varias de estas plantas o frutos tienen la característica de crecer en zonas bajas, a nivel de la tierra como el pepino o en capas subterráneas como el rábano y el cacahuate, con lo que nos viene a la mente la metáfora orientacional "arriba-abajo", donde "arriba" nos ubica en la esfera de las cosas positivas y "abajo" en la esfera de las cosas negativas (Lakoff y Johnson, 1980). Sin ahondar más, aunque el tema merecería todo un estudio aparte, ${ }^{8}$ hay motivos, pues, para sugerir que estos sustantivos propiciaron el deslizamiento semántico hacia nociones cuantificativas de "poco" o "muy poco" porque designaban cosas con

\footnotetext{
${ }^{8}$ La pequeñez también parece haber interactuado, por ejemplo, en la seleccion de pito, definido como 'pequeño instrumento sonoro con el que se produce, soplando, un sonido muy agudo' (DUE, 2000, s.v. pito).
} 
propiedades que suelen evaluarse negativamente: lo común, ${ }^{9}$ lo pequeño, lo bajo.

Cabe señalar que el uso de estos sustantivos para expresar un valor negativo supone un proceso de gramaticalización, esto es, un proceso gradual e irreversible mediante el cual una forma o construcción léxica, a través de determinados contextos, asume una función gramatical, o una forma ya gramatical adquiere una función aún más gramatical (Hopper y Traugott, 2003: 1). Las unidades léxicas que sufren un cambio de esta naturaleza pierden su significado referencial - en un proceso de desgaste que se conoce como vaciamiento semántico (semantic bleaching) - y de manera paralela se enriquecen con el nuevo significado gramatical que asumen (Hopper y Traugott, 2003: 94-98). Así lo comprueban los sustantivos en estudio que dentro de las colocaciones se convierten en elementos funcionales relacionados con la cuantificación. ${ }^{10}$

En el plano formal, la gramaticalización tiende a ir de la mano con un fenómeno de "descategorización", según el cual las unidades léxicas pierden los rasgos morfológicos y privilegios sintácticos que caracterizan a la categoría nominal o verbal para cargarse con atributos de las categorías secundarias como el adjetivo, el participio o la preposición (Hopper, 1991: 22). En nuestro caso, advertimos que los

\footnotetext{
${ }^{9}$ En su acepción 'no especial o selecto' (DUE, 2000, s.v. común).

${ }^{10}$ Como ya dijimos, la conversión de unidades léxicas en cuantificadores parece ser un fenómeno bastante común. Véanse, entre otros, Paradis $(1997,2000)$ y Traugott (2008) con referencia al inglés, y Vega Garfias (2015) y Espinosa Elorza (2012) sobre el uso cuantificativo que han desarrollado algunos adverbios de manera del español.
} 
sustantivos cuantificadores ya no ostentan las propiedades definitorias de la clase nominal, como son la facultad de pluralizarse (valer un pepino/ ${ }^{*}$ valer pepinos), la alternancia entre determinantes (valer un pepino/ ${ }^{*}$ valer $\{e l, t u\}$ pepino), la modificación ( ${ }^{*}$ valer un pepino verde, *valer el pepino que ha sido encurtido), la pronominalización (valer un pepino/ *valerlo) y la libertad posicional (Esa discusión no vale un comino/ ${ }^{\star}$ Un comino no vale esta discusión). ${ }^{11}$ A consecuencia de ese fenómeno de descategorización, el comportamiento de los sustantivos que nos ocupan se aproxima al empleo adverbial e invariable de las formas poco y nada, que también se combinan con valer y que, según comentamos arriba, gradúan la propiedad denotada por el verbo hacia el mismo polo negativo de la escala, si bien cumpliendo su oficio de manera más neutra, por así decirlo, o menos "expresiva”.

Ahora, lo que llama la atención sin duda es el carácter negativo de todas estas colocaciones. No encontramos nada parecido, en los usos de valer, que implique objetos de mucho valor: los cuantificadores gramaticalizados que acompañan a valer están especializados para la graduación de tipo diminutivo. ${ }^{12}$ Surge la pregunta de si es posible dar cuenta

${ }^{11}$ La gramaticalización de estos sustantivos se discute más ampliamente en Arrington Báez (2014). Como nos señala muy acertadamente uno de los revisores anónimos de este trabajo, la descategorización de los sustantivos en estudio no es absoluta sino parcial, ya que, en efecto, son posibles construcciones como vale puro cacahuate en las que el sustantivo aparece con un modificador. Abajo, en (14), ofrecemos otros ejemplos (de lengua hablada) que ilustran el grado intermedio de gramaticalización en que se encuentran los sustantivos que estamos analizando.

${ }^{12}$ El estudio de las colocaciones ha puesto en evidencia que algunos ítems léxicos propician combinaciones con elementos negativos. Estos elementos, se dice, 
de semejante preferencia combinatoria acudiendo a la estructura semántica de valer (véase Boas, 2008). Y a modo de respuesta, podría sugerirse que la orientación positiva del verbo ('tener valor') hizo que los hablantes sintieran mayor presión para generar estrategias de atenuación que les permitían descalificar a las personas o cosas con formas más contundentes que poco o nada. Visto así, el empleo innovador de aquellos sustantivos implicaría entonces un fenómeno de subjetivización, si por subjetivización se entiende cualquier intento de imprimir mayor fuerza expresiva a un enunciado (Traugott, 1995). Los sustantivos cuantificadores como pepino, comino o bledo podrían analizarse, en esta perspectiva, como elementos que refuerzan la actitud subjetiva del hablante (véase Paradis, 2000).

\subsection{El papel del verbo importar en la evolución de valer}

Al inicio de la sección 4, señalamos que la unión de valer con ese tipo de sustantivos cobra visibilidad en la muestra de datos pertenecientes al siglo xx. En realidad, el uso es mucho más antiguo, como pudimos darnos cuenta al ampliar nuestra búsqueda en el CORDE. En esta nueva investigación, encontramos algunos ejemplos anteriores al siglo $\mathrm{xx}$ en los que valer aparece con un sustantivo cuantificador similar a los que estamos analizando. El primer ejemplo que registramos data del siglo xII y contiene el sustantivo figo (higo):

contribuyen a la desfavorable "prosodia semántica" del ítem en cuestión (Granger y Paquot, 2008: 31). 
(9) Non es uerdad non se que digo, todo esto non uale uno figo (Anónimo, Auto de los Reyes Magos, c. 1180, CORDE)

El ejemplo confirma lo dicho por otros estudiosos respecto a que, en aquella época, un figo se utilizaba con distintos verbos para expresar una noción de pequeña cantidad (Menéndez Pidal, 1964, s.v. figo). A la vez muestra que el empleo figurado de ciertos sustantivos en una valoración cuantitativa con fines de realce estuvo presente en la lengua española desde las fases más remotas de su historia.

Sin embargo, por lo que a valer se refiere, es importante subrayar que las combinaciones del verbo con un sustantivo de ese tipo representan un fenómeno de carácter absolutamente esporádico a lo largo del tiempo, hasta llegar al siglo xx. Así lo sugiere nuestra exploración en el CORDE en busca de los ejemplos de valer construidos con uno de esos sustantivos. ${ }^{13} \mathrm{Y}$ esto explica por qué en el corpus de datos que sirvió de base para nuestro estudio (véase supra, $\$ 1$ ), no aparecieron tales ejemplos en las muestras anteriores a la del siglo xx. Por lo tanto, hay razones para argumentar que el auténtico fenómeno de colocación, esto es, de combinación frecuente de dos o más palabras, que definimos arriba para valer, arranca en el siglo xx.

Lo anterior, claro está, conduce a plantearnos la pregunta acerca de las causas que desencadenaron dicho fenómeno tardío en la historia de valer. La idea que queremos defender

\footnotetext{
${ }^{13}$ Los resultados de nuestra búsqueda son los siguientes: s. XIII, 2 casos (figo); s. XIV, 3 casos (figo); s. Xv, 5 casos ( 4 figo, 1 pepino); s. XVI, 7 casos ( 5 higo, 1 comino, 1 pito); s. XVII, 11 casos (10 higo, 1 pito); s. XVIII, 5 casos ( 3 pito, 2 comino); s. XIX, 14 casos (4 comino, 4 pito, 3 pepino, 3 bledo).
} 
en este trabajo es que el fenómeno se difundió con valer por imitación del verbo importar. ${ }^{14}$ En un momento brindaremos evidencia a favor de esta propuesta. Por lo pronto conviene tomar en cuenta que los cambios no ocurren en un vacío; afectan elementos que forman parte de un sistema gramatical (Fischer, 2007) y entre los cuales existen obvias interconexiones (Bybee y McClelland, 2005). El concepto de una red de vinculaciones ayuda a entender que un elemento pueda influir sobre el desarrollo de otro, en particular, si se trata de dos unidades que comparten rasgos semánticos y funcionales (De Smet, 2010), como sucede en el caso de valer e importar.

El verbo importar, en efecto, significa 'tener valor o interés para alguien cierta cosa o cierta persona' (DUE, 2000, s.v. importar). Al igual que valer, pues, el verbo importar sirve para emitir un juicio positivo acerca de algo o alguien, pero con la diferencia de que el significado de importar contiene una referencia obligatoria a la persona en quien la entidad evaluada suscita una actitud positiva (cf. para alguien). Por este motivo, importar se reúne con los verbos mentales que “indican una reacción psíquica en un sujeto" (Cano Aguilar, 1987: 236) y requieren la participación de una persona que desempeña el papel semántico de "experimentante". Obsérvese, además, que importar denota un proceso interno que también se puede graduar (importar mucho, poco o nada), por lo que no debe extrañarnos que importar atraiga com-

\footnotetext{
${ }^{14}$ Para la comprobación de esta hipótesis, se efectuaron nuevas búsquedas adicionales de datos, tanto en el CORDE como en el CREA.
} 
plementos gradativos similares a los de valer y caracterizados por su mayor expresividad.

Encontramos, efectivamente, que tras su introducción en la lengua hacia finales del siglo $\mathrm{xv},{ }^{15}$ importar se suma a los verbos que de vez en cuando se combinan con un sustantivo empleado en sentido figurado para la cuantificación. Así, en este ejemplo del siglo Xvi:

(10) Líbreos Dios de villanos [...]. Y si dan en perseguir, serán perjuros mil veces en lo que no les importa una paja, sino sólo hacer mal (Mateo Alemán, Primera parte de Guzmán de Alfarache, 1599, CORDE)

Lo interesante es que, en un principio, sucede con importar lo que observamos con valer: durante varios siglos, las oraciones de ese tipo constituyen casos aislados y marginales, que no responden a la definición de la "colocación", socializada, memorizada y repetida. ${ }^{16}$ Pero esta situación cambia en el siglo xIx. El cambio se vislumbra no sólo en el incremento de las construcciones en cuanto a su frecuencia (69 ejemplos), sino también en el hecho de que se van formando claras preferencias combinatorias con determinados sustantivos, entre los cuales, en aquel siglo, resaltan bledo (31/69), comino (15/69), rábano (11/69) y pito $(5 / 69)$.

\footnotetext{
${ }^{15}$ Importar desciende del latín IMPORTĀRE 'introducir, llevar adentro'. Corominas y Pascual (1981, s.v. portar) puntualizan que el sentido figurado (mental) del verbo debió de aparecer en bajo latín ya que es común a todos los romances.

${ }^{16}$ Importar arroja el siguiente panorama durante los primeros siglos de su trayectoria: s. XVI, 1 caso (paja); s. XVII, 7 casos (3 pelo, 2 bledo, 1 alverjones, 1 clavo); s. XVIII, 21 casos (13 bledo, 2 higo, 2 comino, 2 pito, 2 diablo).
} 
Estos datos preparan el terreno para la expansión y generalización del uso de estas colocaciones con importar durante el siglo xx (542 ejemplos). En (11), ofrecemos algunos ejemplos :

(11) a. No quieren tener problemas. Son unos rosquetes. Les importa un comino que se muriera el Esclavo (Mario Vargas Llosa, La ciudad y los perros, Perú, 1962, CREA)

b. ¡La gente me importa un carajo! -exclamó como un poseído (Jesús Díaz, La piel y la máscara, Cuba, 1996, CREA)

c. Por lo que yo sé, nunca le importó un rábano vender muebles (William Shand, La transacción, Argentina, 1980, CREA)

d. Que se creyeran éstos que Xaviera pudiese ser alguna rubia peligrosa, amazónica y misteriosa musa de la Organización, no importaba un bledo (Jorge Semprún, Autobiografía de Federico Sánchez, España, 1977, CREA)

Como puede verse, los ejemplos provienen de distintos países y confirman el carácter panhispánico de estas colocaciones. En la mayoría de los ejemplos, importar va acompañado de su argumento dativo (cf. les, me, le), que codifica al experimentante del estado mental denotado por el verbo. Sin embargo, el significado de 'tener valor o interés para alguien cierta cosa o cierta persona' se activa igualmente sin el dativo explícito, como sucede en (11d), donde la presencia de una(s) persona(s) indefinida(s) para quien(es) el sujeto tiene valor o interés se sobreentiende. Insistimos en este 
punto, ya que tiene implicaciones para la historia de valer que se aclararán más adelante (véase infra, \$5).

Si comparamos ahora la evolución de importar con la de valer, podemos establecer que el fenómeno de colocación, en el caso de importar, se inicia en siglo XIX, cuando valer, con sus escasos 14 ejemplos (véase la nota 13), aún no da muestra de estarse moviendo en esa dirección, hasta que en el siglo xx, ya afianzado el fenómeno con importar, empieza a cobrar visibilidad la predisposición de valer a combinarse con el mismo tipo de sustantivo cuantificador. Los datos de frecuencia que nos ayudaron a establecer lo anterior están sintetizados en el cuadro 1.

Cuadro 1. Evolución de las colocaciones con nombres que significan 'poco'

\begin{tabular}{|c|c|c|c|c|c|c|c|c|}
\hline Siglos & XIII & XIV & XV & XVI & XVII & XVIII & XIX & XX \\
\hline importar & & & & 1 & 7 & 21 & 69 & 542 \\
\hline valer & 2 & 3 & 5 & 7 & 11 & 5 & 14 & 63 \\
\hline
\end{tabular}

Nótese que el desfase temporal entre una y otra evolución - más temprana en el caso de importar y más tardía en el caso de valer - se ve apoyado por una aparente diferencia en los niveles de arraigo de las respectivas colocaciones. Según reflejan los datos correspondientes al siglo xx (y las primeras décadas del xxi), el uso de las colocaciones con importar está ya perfectamente integrado en la lengua culta o literaria (441 de los 542 ejemplos que recogimos provie- 
nen del rubro "libros" en el CREA), mientras que su empleo con valer, en cierta medida, sigue vinculado a registros más coloquiales (26 de los 63 ejemplos documentados - 41\%pertenecen a los géneros "prensa" y "oral” del CREA).

En esta sección, para concluir, tratamos la combinatoria de valer con sustantivos referidos a objetos de escaso valor y propusimos que el fenómeno de "colocación" que evidencian dichas combinaciones se forjó sobre el modelo de importar. Como dijimos, la posibilidad de que un elemento del sistema lingüístico influya sobre el desarrollo de otro no sorprende si el sistema se visualiza como una red conformada por elementos interconectados que abren paso a mutuos acercamientos cuando poseen rasgos afines (De Smet, 2010). En el caso que nos ocupa, el rastreo diacrónico de las colocaciones que hicimos para ambos verbos nos permitió ver un proceso emergente de fijación asociado con el siglo XIX, en la historia de importar, seguido de un proceso afín que afectó a valer un siglo más tarde. También observamos que hoy en día las colocaciones en estudio son mucho más frecuentes con importar que con valer y se utilizan con mayor libertad a lo ancho del mundo hispánico.

Lo que falta por exponer es el argumento más fuerte que puede aducirse a favor de la hipótesis de que importar actuó como modelo para valer. Involucra otro paso en la evolución de valer, que pretendemos abordar enseguida. 


\section{Deslizamiento de valer hacia el campo mental}

El siguiente paso se relaciona con la presencia de un ser humano codificado como objeto indirecto que registramos en algunas de las colocaciones discutidas arriba:

(12) a. Anoche hubo una misa, que a nadie le vale un comino, porque la celebraron unos ociosos, faltos de oficio, que se fingieron frailes (Tomás Carrasquilla, La marquesa de Yolombó, 1928, CORDE)

b. A Philip Marlowe Ir. le valía un bledo lo que sucediera en Chez Georges (Daniel Leyva, Una piñata llena de memoria, 1984, CREA)

En estos ejemplos el significado de valer cambia, y se le reconoce otra acepción próxima a 'importar. Obsérvese que en algunas regiones, como México, por ejemplo, el uso de valer en este tipo de contexto está suficientemente arraigado para merecer una entrada de diccionario. El Diccionario del español de México, elaborado bajo la dirección de Luis Fernando Lara, lo define en estos términos (DEM, 1990, s.v. valer):

IV.4. Valerle un cacahuate o valerle un comino (Coloq). Importarle poco alguien o algo a una persona.

Me vale un comino que tú seas el jefe.

Le vale un cacahuate todo el trabajo que se hace aquí.

Esta entrada no tiene correspondencia ni en el Diccionario de la Real Academia Española ni en el Diccionario de uso 
del español de María Moliner, de lo que cabe inferir que el desarrollo de valer que estamos analizando se ha circunscrito a determinadas zonas de la comunidad hispanohablante.

Arriba (véase supra, \$4.2) comentamos que en sus colocaciones con objetos de poco valor, el verbo importar puede prescindir del experimentante dativo sin afectar la interpretación de las oraciones. Ahora queremos mostrar que la situación es distinta con valer. Para darnos cuenta de ello, volvamos a uno de los ejemplos presentados en (12) y veamos qué pasa si eliminamos el dativo:

(13) a. Anoche hubo una misa, que a nadie le vale un comino, porque la celebraron unos ociosos, faltos de oficio, que se fingieron frailes (Tomás Carrasquilla, La marquesa de Yolombó, 1928, CORDE)

a'. ? Anoche hubo una misa, que $\varnothing$ vale un comino, porque la celebraron unos ociosos, faltos de oficio, que se fingieron frailes.

En presencia del dativo (13a), surge la interpretación 'importarle poco alguien o algo a una persona' que define el Diccionario del español de México; en su ausencia (13a'), valer no logra transmitir el significado mental. Al suprimirse el dativo, la colocación recobra el sentido de 'valer muy poco' que discutimos en la sección anterior.

La comparación entre los dos verbos pone de relieve una distinción muy clara que apunta al origen del nuevo significado de valer. Frente al dativo de importar, que está siempre presente, explícita o implícitamente, en efecto, el experimentante dativo con valer constituye un elemento 
adicional y necesario para disparar la acepción mental del verbo, a semejanza de importar. De este modo, la comparación hace evidente que las colocaciones con sustantivos gramaticalizados sirvieron de escenario para la emergencia del significado 'importarle poco alguien o algo a una persona' que valer desarrolló imitando el comportamiento del verbo importar.

Dicho cambio, como ya se señaló, está restringido a algunas variedades del español, motivo por el cual las documentaciones del uso mental de valer que arroja el CREA son escasas. En México y otras regiones americanas, por el contrario, el nuevo significado tiene mucha vitalidad, sobre todo en la lengua hablada. Esto se hace manifiesto cuando se navega por el Internet buscando las ocurrencias de valer en las redes sociales como facebook, twitter y google+, donde los hablantes se expresan con un mayor grado de espontaneidad al estar dentro de un ámbito informal y de confianza. El examen de las fuentes informales revela, además, que los hablantes dan muestra de su creatividad a la hora de seleccionar y manipular los sustantivos cuantificadores que acompañan al verbo valer. Sirvan de ilustración los siguientes ejemplos:

(14) a. Me vale madre si no te caigo bien, total yo no vivo para complacerte.

(http://muchasfrases2.blogspot.mx/2010/08.html)

b. A mi me vale un reverendo camote todo eso, yo vivo de la manera que creo "correcta" y punto.

(http://eltrouble.blogspot.mx/2006_02_01_archive.html)

c. Si salta tu banda pues me vale queso le salta la mia. 
(http://www.facebook.com/AdanZapataPaginaOficialFans/posts/468889779864636)

d. Odias a one direction? tu opinion me vale hongo. (https://www.facebook.com/FansDeTomasDeVioletta)

e. Hay mil mejores formas de perder el tiempo y tambien me vale una puta chingada lo que hagas con el. (http://planeta-caravana.blogspot.mx/2010/02/top-10100-apodos-horrendos-del-futbol.html)

f. Me vale gorra que tengas otras deudas. A mi me pagas ahora.

(http://www.tubabel.com/definicion/12356-me-valegorra)

La diversidad de formas constituye un reflejo muy claro de la productividad que ha alcanzado la construcción que nos ocupa en algunas hablas hispanoamericanas, entendida la productividad como la tendencia a extender un patrón de uso a nuevas formas (McClelland y Bybee, 2007: 439). A diferencia de las unidades fraseológicas, las colocaciones, que contienen elementos variables, admiten innovaciones (Wotjak, 1998), y éstas suelen elaborarse sobre la base de los ejemplares más comunes, sustituyendo elementos de significado similar (Bybee y Eddington, 2006).

En resumen, dedicamos esta sección a la génesis de la acepción 'importarle poco alguien o algo a una persona' que valer desarrolló a partir de sus colocaciones con sustantivos cuantificadores. El cambio ocurre en el siglo xx, época en la que este tipo de colocación se difunde de manera espectacular con importar y en la que valer, por imitación de importar, según nuestra hipótesis, comienza a atraer a un 
experimentante dativo que empuja su significado hacia el campo mental.

El aspecto llamativo del cambio radica en que la influencia de importar sobre valer no se dio de manera uniforme en todas las variedades del español, ya que sólo en algunas, según vimos, valer adoptó el argumento dativo de su modelo. Es decir, aunque existían condiciones idóneas para la innovación, muchas comunidades hispanohablantes no la llevaron a cabo, con lo cual vuelve a verificarse que el cambio lingüístico no es nunca "necesario", sino sólo posible (Harris y Campbell, 1995: 6).

En los países, tales como México, donde el experimentante dativo echó raíces, valer adquirió un nuevo significado de carácter mental. El verbo se transforma en el interior de un tipo específico de construcción - las colocaciones con un sustantivo referido a una cosa de escaso valor- y asimismo proporciona evidencia a favor del papel central que juegan los contextos de uso en el cambio lingüístico (Bybee, Perkins y Pagliuca, 1994; Heine, 2002; Traugott, 2004).

Cabe observar, también, que la extensión de valer al dominio de los estados mentales tiene por efecto el reacomodo de su valencia. No siempre sucede que un cambio de significado vaya de la mano con un cambio en el plano formal (Traugott, 2008). Pero en el caso de valer es claro que hubo convergencia: la estructura argumental de valer se expande (+ dativo) con el nacimiento de la acepción 'importar'. 


\section{El sentido negativo de valerle}

El último desarrollo que examinaremos en este trabajo nos vuelve a los ejemplos ilustrados en (1) y repetidos aquí para mayor comodidad del lector:

(15) a. ¡Me vale! Para mí lo nuestro terminó para siempre (Felipe Victoria Zepeda, La casta divina. Historia de una narcodedocracia, Novela sobre la impunidad presidencial, 1995, CREA)

b. Se encogió de hombros, "me vale”, trató de convencerse (Jenny E. Hayen, Por la calle de los anhelos, 1993, CREA)

Al inicio de nuestro trabajo, mencionamos que la frase me (te, le) vale comunica la idea de que algo no le importa a alguien y destacamos que su peculiaridad reside en que una forma aparentemente afirmativa en la superficie sea capaz de transmitir un sentido negativo.

Queda claro ahora que este empleo de valer se enlaza con el cambio visto en la sección anterior, ya que supone la acepción mental de 'importar', lo cual explica por qué se halla restringido a las zonas de habla, como la mexicana, donde se difundió el cambio.

Antes de ahondar en el origen de la frase, es necesario señalar que la forma por la que los hablantes en las redes sociales (véase supra, \$5) se inclinan de manera preferencial es el sustantivo madre(s). De hecho, el uso de madre(s) en estas colocaciones está muy afianzado, de modo que llega a hacerse presente en algunas obras recogidas en el CREA: 
(16) a. Qué puedo hacer, manito. Ana Luisa me vale madre (Marco Antonio Campos, Que carne es hierba, México, 1982, CREA)

b. ¡Cabrón! - me dice - qué no sientes nada, toda esa gente ¡te vale madres! (David Martín del Campo, Las rojas son las carrateras, México, 1976, CREA)

b. Bueno, dije, ni pedo, va a ser cosa de alucinar un rato dos o tres sensaciones y entregar el equipo. Eso es lo malo, lo preocupante, que al final me valió madres (Gerardo María, Fábrica de conciencias descompuestas, México, 1980, CREA)

c. Pero no lo critico, hace usted bien, le vale madres todo, en cambio nosotros tenemos miedo, ¡miedo!, esa es la pura neta (Enrique Espinosa, Jesús el bisabuelo y otros relatos, México, 1995, CREA)

Al igual que pepino, rábano o bledo, el sustantivo madre(s) aporta la idea del poco valor que se atribuye al sujeto de la predicación. Según comenta Rodríguez Cortés (2010), el empleo de madre(s) con sentido negativo, en ésta y otras construcciones, obedece a procesos de desvalorización que afectan a una figura respetada socialmente y está motivado por el deseo de lograr determinados efectos expresivos - amenaza, insulto, burla - que tienen algo en común con la transgresión de un tabú.

Ahora, aunque las expresiones negativas con madre(s) son relativamente comunes en el habla, siguen siendo objeto de censura por considerarse groseras. Y esto nos proporciona una clave para entender cómo valer, con dativo pero sin complemento cuantificador, pasó a significar 'no importarle 
a alguien una cosa o persona' El camino se vislumbra en la entrada IV.5 del Diccionario del español de México, bajo la cual están reunidos dos ejemplos con madre(s) y uno que carece del sustantivo:

IV.5. Valer(le) (madre o madres) (Puede ser grosero). No importar o no importarle a alguien una cosa o persona.

Ese güey vale madres.

Me vale madre que tú ya no me quieras.

Esos rumores me valen.

Desde esta perspectiva, la frase que estamos discutiendo sería producto de una elipsis. La elipsis, que remite a la "supresión en la construcción de algún elemento sin que quede afectada la claridad del sentido" (DUE, 2000, s.v. elipsis), puede constituirse en un proceso de cambio, en la medida en que la parte que se conserva de la expresión compleja adquiere el significado del todo (Luján, 2010: 292). En nuestro caso, diríamos, pues, que me vale hereda el significado negativo que tenía me vale madres. Y agregaríamos que la frase debió emerger en contextos discursivos en que el hablante pretendía esquivar una grosería, si bien con la seguridad de que el oyente no tendría dificultad alguna para restituir el complemento omitido.

La otra posibilidad, sin embargo, es que se trate de un fenómeno más general, que no pase forzosamente por madre(s). En esta segunda propuesta, dada la productividad de la construcción cuantificada de valer con objetos de poco valor, el verbo habría terminado por absorber la polaridad negativa de los cuantificadores. Aquí tendríamos entonces 
un fenómeno de "contagio" (Luján, 2010: 297). De acuerdo con este proceso de cambio, el sentido de una palabra se transfiere a otra debido a que las dos palabras ocurren juntas en muchos contextos. El ejemplo más citado para ilustrar el fenómeno de contagio proviene del francés, en el que algunos vocablos desarrollaron un sentido negativo a raíz de que solían combinarse con la partícula negativa ne, entre otros, el sustantivo pas 'paso' (Lujan, 2010: 297). Como producto del contagio, hoy en día, en el francés coloquial, la estructura negativa ne ... pas se está reduciendo a la partícula de refuerzo pas, que niega en ausencia de ne (cf. je sais pas '(yo) no sé). Algo similar podría invocarse para justificar el sentido negativo de valer en una frase que ya no incluye el sustantivo cuantificador que llevaba la carga negativa.

Independientemente de cuál de las dos propuestas se quiera adoptar, ha quedado claro que el desarrollo de valer que tratamos en esta sección tiene su origen en aquellas colocaciones formadas con objetos de escaso valor (o desvalorizados), que los hablantes aprovechan en el discurso para emitir juicios negativos acerca de las cosas (- dativo) o para expresar su propia reacción negativa ante ellas (+ dativo). Y si estamos en lo correcto al proponer que las colocaciones de valer se gestaron y difundieron bajo el influjo de importar, merece la pena señalar que valer dio un paso más respecto a su modelo, pues me importa nunca significa 'no me importa'. La capacidad para activar una negación en el seno de una frase afirmativa es un rasgo propio de la evolución de valer. 


\section{Conclusiones}

Nuestro trabajo se centró en el verbo valer del español, que desciende del latín valēre y hereda de su fuente la denotación de una propiedad, asociada típicamente con la clase de los adjetivos. En latín, valĒre parte de una noción de robustez física y, pasando por una idea más abstracta de 'poder', extiende su aplicación a personas o cosas que tienen 'valor'. Dependiendo del contexto, la propiedad poco específica de 'tener valor' se carga de matices ligados al mérito, la vigencia, la eficacia o la utilidad. Ésta es la acepción con que valere empieza su trayectoria en español, antes de sufrir varias modificaciones que desembocan en el significado mental de 'no importar', que se ha desarrollado en algunas partes del territorio hispanohablante.

Según nuestra propuesta, dicho significado se deriva del empleo cuantificado de valer en colocaciones formadas con sustantivos que evocan objetos de escaso valor (valer un pepino, un comino, etc.) y contribuyen a disminuir la intensidad con que el sujeto de la predicación posee la cualidad expresada por el verbo.

La propensión de valer a aparecer con complementos de cantidad no es motivo de sorpresa. Entendemos que se debe a que las propiedades se pueden graduar y observamos que a lo largo de los siglos valer atrae la cuantificación gradativa (valer mucho o poco, valer más o menos que). En ese sentido, nuestro objeto de estudio apoya la idea de que el comportamiento sintáctico de un verbo está en buena medida motivado por su estructura semántica (Levin y Rappaport Hovav, 2005). 
El tipo particular de aquellas colocaciones, en cambio, no era previsible. Viene a recordarnos que la historia de las palabras siempre incluye giros inesperados, que surgen en el habla, alteran el significado y justifican la insistencia con la que algunos estudiosos continúan enfatizando la naturaleza caótica y escurridiza de la evolución de las unidades léxicas (Hock y Joseph, 1996: 252).

Sin embargo, en retrospectiva, se alcanza a percibir cierto orden en medio del caos. Así, en el caso de valer, aquellas colocaciones se pueden aclarar si se pone atención en las afinidades semánticas que existen entre el objeto de estudio e importar y que son susceptibles de provocar acercamientos dentro de una red de elementos interconectados (Bybee y McClelland, 2005). Advertimos la identidad de las colocaciones, encontramos evidencia diacrónica y sincrónica para argumentar que importar influyó sobre el desarrollo de valer, y suponemos que las colocaciones con ambos verbos obedecen a la necesidad que sintieron los hablantes de contar con frases más expresivas que poco o muy poco para diluir o negar la orientación positiva de los lexemas verbales.

A partir de ahí, el camino por el que valer se desliza hacia el campo mental se puede explicar, aunque tampoco era previsible ni logró generalizarse en toda la lengua. Este camino involucra la adopción del argumento dativo de importar, en el interior de las colocaciones, antes de dar paso, por elipsis o por contagio, a la frase valerle con su significado de 'no importarle a alguien una cosa o persona'.

Al mismo tiempo, la historia de valer nos brinda la oportunidad de vislumbrar algunas de las grandes tendencias que 
caracterizan al cambio semántico (véanse Traugott y Dasher, 2005, para un panorama general de estas tendencias). Permite observar, por ejemplo, el uso de la metáfora en la extensión del significado de VALĒRE desde la fuerza física hacia el concepto más abstracto de 'valor', así como un proceso metonímico en el vínculo establecido entre objetos insignificantes y la noción de poca cantidad. Respecto a estas colocaciones, presupone un mecanismo de inferencia pragmática que hace posible la re-interpretación de los sustantivos como cuantificadores y evidencia la gramaticalización de dichos sustantivos, con los sabidos efectos del fenómeno en el plano semántico y el morfo-sintáctico.

La historia de valer contiene, además, varios reflejos de la tendencia de las palabras a generar significados más subjetivos, esto es, significados que expresan las creencias del hablante o su actitud ante lo dicho. La subjetivización está implicada en la diferencia entre retratar a una persona robusta y juzgar el valor que posee alguien o algo; se manifiesta en las estructuras cuantificadas que ponen en juego una norma implícita conforme a las expectativas del hablante; y se perfila en el uso innovador de sustantivos tales como pepino, bledo o madre(s), en lugar de poco o muy poco, para dar refuerzo a la carga negativa del juicio que se emite.

Más allá de los mecanismos que operan en el cambio semántico — metáfora, metonimia, inferencia pragmática, gramaticalización, subjetivización-, la historia de valer pone a la vista el hallazgo de que las palabras no se transforman de forma aislada, sino insertadas en contextos específicos de uso y sometidas a la influencia que sobre ellas ejercen los elementos con los cuales se combinan. 
Y, por último, confirma que entre los factores que motivan el cambio semántico figura de manera prominente el poder de la analogía. El pensamiento analógico garantiza la capacidad de los seres humanos para percibir similitudes y establecer conexiones entre las cosas y funciona asimismo como condición previa para el cambio (Traugott y Trousdale, 2010). En la historia de valer, fue la analogía la que indujo a los hablantes a relacionar la cualidad de 'ser fuerte' con la propiedad de 'tener valor', a reconocer los traslapes entre $v a$ ler e importar, a visualizar el potencial cuantificativo que tenían determinados sustantivos y a ensanchar el conjunto de estos sustantivos con nuevos miembros vistos como afines.

La observación de que estas mismas tendencias se repiten entre lenguas y épocas sugiere que existen patrones comunes en la manera en que los seres humanos producen sus mensajes y los procesan (Traugott y Dasher, 2005: 36). De ahí, el énfasis actual en las regularidades del cambio semántico, con la clara intención de disipar todo lo idiosincrásico, variable y caprichoso que solía atribuírsele en el pasado. No obstante, sigue habiendo algo de verdad en que cada palabra, como se decía antes, tiene su propia historia.

\section{Corpus}

CORDE. Real Academia Española. Banco de datos (CORDE) [en línea]. Corpus Diacrónico del Español. http://www.rae.es CREA. Real Academia Española. Banco de datos (CREA) [en línea]. Corpus de Referencia del Español Actual. http:// www.rae.es 


\section{Bibliografía}

Alarcos Llorach, Emilio (1994), Gramática de la lengua española, Madrid, Espasa Calpe.

Arrington BÁez, J. Elenor (2014), Estudio diacrónico del verbo 'valer', Universidad Nacional Autónoma de México, tesis de maestría.

Blank, Andreas (1999), "Why do new meanings occur? A cognitive typology of the motivations for lexical semantic change", en A. Blank y P. Koch (eds.), Historical semantics and cognition, 61-89. Berlín / Nueva York, Mouton de Gruyter.

BoAs, Hans (2008), "Towards a frame-constructional approach to verb classification", Revista Canaria de Estudios Ingleses, 57, pp. 17-47.

Bybee, Joan y David Eddington (2006), "A usage-based approach to Spanish verbs of 'becoming'", Language, 82, pp. 323-355.

y Paul Hopper (eds.) (2001), Frequency and the emergence of linguistic structure, Ámsterdam / Filadelfia, John Benjamins.

y James L. McClelland (2005), "Alternatives to the combinatorial paradigm of linguistic theory based on domain general principles of human cognition", The Linguistic Review, 22, pp. 381-410.

, Revere Perkins y William Pagliuca (1994), The evolution of grammar. Tense, aspect, and modality in the languages of the world, Chicago, Chicago University Press. 
CAno Aguilar, Rafael (1987), Estructuras sintácticas transitivas en el español actual, Madrid, Gredos.

Corominas, Joan y José A. Pascual (1981), Diccionario crítico etimológico castellano e hispánico, vol. 4, Madrid, Gredos.

Demonte, Violeta (1999), "El adjetivo: clases y usos. La posición del adjetivo en el sintagma nominal", en I. Bosque y V. Demonte (dirs.), Gramática descriptiva de la lengua española, vol. 1, Madrid, Espasa Calpe, pp. 129-215.

Di Tullio, Ángela (2007), Manual de gramática del español, $2^{\text {a }}$ ed., Buenos Aires, La isla de la luna.

Espinosa Elorza, Rosa María (2012), “Cambios sintácticos en el siglo XIX”, en J. L. Ramírez Luengo (ed.), Por sendas ignoradas. Estudios sobre el español del siglo XIX, Lugo, Axac, pp. 61-74.

Fischer, Olga (2007), Morphosyntactic change: Functional and formal perspectives, Oxford, Oxford University Press.

Granger, Sylviane y Magali Paquot (2008), “Disentangling the phraseological web", en S. Granger y F. Meunier (eds.), Phraseology. An interdisciplinary perspective, Ámsterdam / Filadelfia, John Benjamins, pp. 27-49.

Gries, Stefan Th. (2008), "Phraseology and linguistic theory. A brief overview”, en S. Granger y F. Meunier (eds.), Phraseology. An interdisciplinary perspective, Ámsterdam / Filadelfia, John Benjamins, pp. 3-23.

Harris, Alice C. y Lyle Campbell (1995), Historical syntax in cross-linguistic perspective, Cambridge, Cambridge University Press. 
HeIne, Bernd (2002), "On the role of context in grammaticalization", en I. Wischer y G. Diewald (eds.), New reflections on grammaticalization, Ámsterdam / Filadelfia, John Benjamins, pp. 83-101.

$\longrightarrow$ Ulrike Claudi y Friederike Hünnemeyer (1991), Grammaticalization: A conceptual framework, Chicago, Chicago University Press.

Hock, Hans Henrich y Brian D. Joseph (1996), Language history, language change, and language relationship. An introduction to historical and comparative linguistics, Berlín / Nueva York, Mouton de Gruyter.

Hopper, Paul J. (1991), “On some principles on grammaticization", en E. C. Traugott y B. Heine (eds.), Approaches to grammaticalization, vol. 1, Ámsterdam / Filadelfia, John Benjamins, pp. 17-35. y Elizabeth Closs Traugott (2003), Grammaticalization, $2^{\text {a }}$ ed., Cambridge, Cambridge University Press. Írsula PeÑA, Jesús (1992), “Colocaciones sustantivo-verbo", en G. Wotjak (ed.), Estudios de lexicología y metalexicografía del español actual, Tubinga, Max Niemeyer, pp. 159-167.

Krug, Manfred G. (2001), "Frequency, iconicity, categorization: Evidence from emerging modals", en J. Bybee y P. Hopper (eds.), Frequency and the emergence of linguistic structure, Ámsterdam / Filadelfia, John Benjamins, pp. 309-335.

LAkoff, George y Mark Johnson (1980), Metaphors we live by, Chicago, Chicago University Press.

LARA, Luis Fernando (dir.) (1990), Diccionario del español de México, México, El Colegio de México. 
Levin, Beth y Malka Rappaport Hovav (2005), Argument realization, Cambridge, Cambridge Uiversity Press.

Luján, Eugenio R. (2010), "Semantic change”, en S. Luraghi y V. Bubenik (eds.), The continuum companion to historical linguistics, Londres / Nueva York, Continuum, pp. 286-310.

McClelland, James L. y Joan Bybee (2007), "Gradience of gradience: A reply to Jackendoff”, The Linguistic Review, 24, pp. 437-455.

Menéndez Pidal, Ramón (1964), Cantar de mio Cid. Texto, gramática y vocabulario. Tercera parte: Vocabulario, $4^{\mathrm{a}}$ ed., Madrid, Espasa Calpe.

Moliner, María (2000), Diccionario de uso del español, Madrid, Gredos.

Paradis, Carita (1997), Degree modifiers of adjectives in spoken British English, Lund, Lund University Press.

(2000), "Reinforcing adjectives: A cognitive semantic perspective on grammaticalization", en R. BermúdezOtero, D. Denison, R. M. Hogg y C. B. McCully (eds.), Generative theory and corpus studies, Berlín / Nueva York, Mouton de Gruyter, pp. 233-258.

Pimentel Álvarez, Julio (1996), Diccionario: latín-espanol, español-latín. Vocabulario clásico, jurídico y eclesiástico, México, Porrúa.

Real Academia Española (2001), Diccionario de la lengua española, Madrid, Espasa Calpe.

Rodríguez Cortés, Diego Armando (2010), Unidades fraseológicas con 'echar': función y sentido, Universidad Nacional Autónoma de México, tesis de maestría. 
SÁnchez López, Cristina (1999), "Los cuantificadores: clases de cuantificadores y estructuras cuantificativas", en I. Bosque y V. Demonte (dirs.), Gramática descriptiva de la lengua española, vol. 1, Madrid, Espasa Calpe, pp. 1025-1129.

Sincla IR, John M. (1991), Corpus, concordance, collocation, Oxford, Oxford University Press.

Smet, Hendrik De (2010), "Grammatical interference. Subject marker for and the phrasal verb particles out and forth", en E. C. Traugottt y G. Trousdale (eds.), Gradience, gradualness and grammaticalization, Ámsterdam / Filadelfia, John Benjamins, pp. 75-104.

Sweetser, Eve E. (1990), From etymology to pragmatics: Metaphorical and cultural aspects of semantic structure, Cambridge, Cambridge University Press.

Traugott, Elizabeth Closs (1988), "Pragmatic strengthening and grammaticalization", en S. Axmaker, A. Jaisser y H. Singmaster (eds.), Proceedings of the Fourteenth Annual Meeting of the Berkeley Linguistics Society, Berkeley, Berkeley Linguistics Society, pp. 406-416. (1989), "On the rise of epistemic meanings in English: An example of subjectification in semantic change", Language, 57, pp. 33-65.

(1995), "Subjectification in gammaticalisation", en S.

Wright y D. Stein (eds.), Subjectivity and Subjectivisation. Linguistic perspectives, Cambridge, Cambridge University Press, pp. 31-54.

(2003), "Constructions in grammaticalization", en B.

D. Joseph y R. D. Janda (eds.), The handbook of historical linguistics, Oxford, Blackwell, pp. 624-647. 
Traugott, Elizabeth Closs (2004), "Historical pragmatics", en L. R. Horn y G. L. Ward (eds.), The handbook of pragmatics, Londres, Blackwell, pp. 538-561. (2008), "The grammaticalization of NP of NP patterns", en A. Bergs y G. Diewald (eds.), Constructions and language change, Berlín / Nueva York, Mouton de Gruyter, pp. 23-45.

y Richard B. DAsher (2005), Regularity in Semantic Change, Cambridge, Cambridge University Press. y EKKEHARD KöNIG (1991), “The semantics-pragmatics of grammaticalization revisited", en E. C. Traugott y B. Heine (eds.), Approaches to grammaticalization, vol. 1, Ámsterdam / Filadelfia, John Benjamins, pp. 189-251. y Graeme Trousdale (2010), "Gradience, gradualness and grammaticalization: How do they intersect?", en E. C. Traugott y G. Trousdale (eds.), Gradience, gradualness and grammaticalization, Ámsterdam / Filadelfia, John Benjamins, pp. 19-44.

Vega Garfias, Liliana Irasema (2015), El uso de 'bien' como cuantificador. Un acercamiento diacrónico, Universidad Nacional Autónoma de México, tesis de maestría.

Wotjak, Gerd (1998), “Reflexiones acerca de construcciones verbo-nominales funcionales”, en G. Wotjak (ed.), Estudios de fraseología y fraseografía del español actual, Fráncfort / Madrid, Vervuert-Iberoamericana, pp. 257279. 
